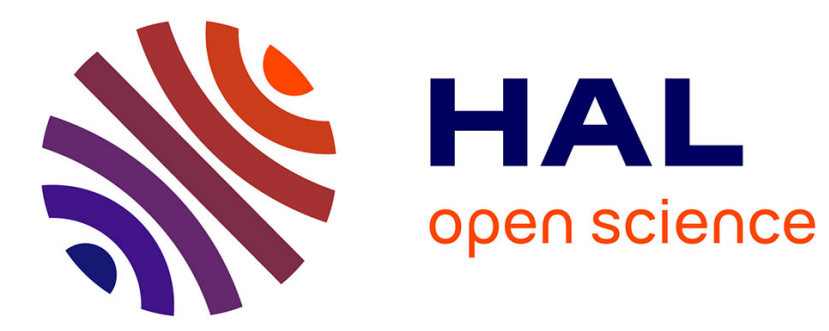

\title{
Magnetic resonance imaging studies of spontaneous capillary water imbibition in aerated gypsum
}

Kyung-Min Song, Jonathan Mitchell, Hamouda Jaffel, Lynn F Gladden

\section{To cite this version:}

Kyung-Min Song, Jonathan Mitchell, Hamouda Jaffel, Lynn F Gladden. Magnetic resonance imaging studies of spontaneous capillary water imbibition in aerated gypsum. Journal of Physics D: Applied Physics, 2011, 44 (11), pp.115403. 10.1088/0022-3727/44/11/115403 . hal-00602612

\section{HAL Id: hal-00602612 https://hal.science/hal-00602612}

Submitted on 23 Jun 2011

HAL is a multi-disciplinary open access archive for the deposit and dissemination of scientific research documents, whether they are published or not. The documents may come from teaching and research institutions in France or abroad, or from public or private research centers.
L'archive ouverte pluridisciplinaire HAL, est destinée au dépôt et à la diffusion de documents scientifiques de niveau recherche, publiés ou non, émanant des établissements d'enseignement et de recherche français ou étrangers, des laboratoires publics ou privés. 


\title{
Magnetic Resonance Imaging Studies of Spontaneous Capillary Water Imbibition in Aerated Gypsum
}

\author{
Kyung-min Song ${ }^{1}$, Jonathan Mitchell ${ }^{1}$, Hamouda Jaffel ${ }^{2}$ and Lynn F Gladden ${ }^{1}$ \\ ${ }^{1}$ Department of Chemical Engineering and Biotechnology, University of Cambridge, \\ Cambridge CB2 3RA, UK \\ ${ }^{2}$ Saint-Gobain Recherche, 39 quai Lucien Lefranc, 93303 Aubervilliers, France \\ E-mail: jm600@cam.ac.uk (Jonathan Mitchell)
}

\begin{abstract}
In this paper we investigate both capillary water imbibition and the sorptivity of aerated gypsum plaster, and how these sorption characteristics are related to the pore structure of the material. These characteristics are examined by monitoring mass change using the conventional gravimetric method and by obtaining water content profiles using nondestructive magnetic resonance imaging (MRI) techniques during capillary imbibition of water. Here, three different gypsum samples are investigated: one non-aerated reference gypsum sample and two aerated gypsum samples produced with different volumetric air fractions. The capillary water absorption into the reference sample follows $t^{1 / 2}$ kinetics (Fickian diffusion), where $t$ is the time of ingress. However, in the aerated gypsum samples there are deviations from $t^{1 / 2}$ kinetics. The MRI results show unambiguously that two wetting fronts advance through the aerated structure; an observation that cannot be made from the gravimetric data alone. The water content profiles of the aerated gypsum samples are therefore analysed by treating them as the sum of two separate absorption processes using Sharp Front (SF) analysis. The capillary water absorption properties of this material are well described as a parallel combination of fast absorption into fine matrix pores and slow absorption into a modified structure of matrix pores inter-connected to air voids introduced into the slurry by aeration.
\end{abstract}

PACS 47.56.+r. flows through porous media

PACS 47.55.nb. capillary and thermocapillary flows

Preprint submitted to Journal of Physics D: Applied Physics 


\section{Introduction}

Gypsum wallboards or plasterboards are used widely in modern construction sites due to their advantageous mechanical properties of low specific gravity, good thermal and sound insulation, and fire resistance [1]. In the commercial manufacture of gypsum plasterboard it is desirable that the product be light in weight in order to meet the growing demand for such materials in many applications of modern construction, and for the convenience of distribution and installation. To reduce the density of gypsum-based products, the water-to-plaster ratio $w / p$ is increased or lightweight aggregates (e.g. perlite and expanded polystyrene) are added [2]. However, an increased $w / p$ requires a higher level of energy expenditure during the drying process, and lightweight aggregates often introduce manufacturing problems due to difficult handling and inefficient mixing. Compared to these methods, aeration of gypsum is an attractive alternative. Aeration involves incorporating pregenerated foam directly into wet gypsum slurry, leading to the formation of air voids within the structure. Subject to the production process, these materials are often referred to as aerated gypsum or foamed gypsum. The study of the mechanical properties and structural characteristics of these lightweight gypsum materials is a relatively new research topic. Recently, the density and strength characteristics [3] and the heat transfer of these materials [4] have been investigated. However, to the best of our knowledge, detailed studies on the capillary water absorption and sorptivity characteristics of these materials are yet to be presented. This paper is aimed at investigating these sorption characteristics of aerated gypsum and how they relate to the pore structure of the material using nondestructive magnetic resonance imaging (MRI). Improved knowledge of the sorption characteristics will be beneficial in predicting the mechanical performance of these materials and hence improving the product quality.

The study of capillary water absorption into porous building materials is of fundamental interest for understanding the mechanical performance and service lifetime of materials, and hence in being able to improve their durability [5]. In recent years, the concept of sorptivity, developed originally from unsaturated flow theory for water transport in soil physics [6-8], has been applied successfully to describe capillary water absorption processes in many porous building materials [9-15]. The total volume of liquid absorbed by a porous building material during one-dimensional capillary absorption is given by

$$
i(t)=k+S t^{1 / 2}
$$

where $i(t)$ is the cumulative volume of liquid absorbed at time $t$ per unit area of surface. $k$ is a constant and $S$ is the sorptivity: a characteristic property of porous materials. This quantity $S$ defines the tendency of a porous building material to absorb and transmit liquid under the action of capillary forces when it is exposed to a wetting liquid source. The sorptivity is now recognized as the most useful parameter to characterize the capillary absorption properties, and hence is considered as a 
measure of the potential durability of many porous building materials [16-19]. A more recent review by Hall [20] gives the theoretical background and practical aspects of assessing the sorptivity of building materials in the laboratory. Since the interpretation of experimental data requires some understanding of the theoretical basis of unsaturated flow, a brief explanation of the theory of sorptivity is given in section 2 [6-10].

The square root of time $t$ dependence of the capillary absorption of liquids by many homogeneous porous building materials is well established [17]. However, capillary absorption data do not always obey standard $t^{1 / 2}$ kinetics. Strong deviations from $t^{1 / 2}$ behaviour have been reported previously in the literature for some materials with open and coarse pore structures, such as cement mortars [16] and poorly compacted concrete [13]. In these studies, the deviation from $t^{1 / 2}$ behaviour was explained by the retarding effect of gravity on vertical capillary rise since these materials contain large voids, i.e. the capillary forces which act in the filling of the large voids are weak and lead to marked deviations from $t^{1 / 2}$ behaviour in capillary rise tests. In such cases, (1) was extended by inclusion of a third term in $t[13,16]$ :

$$
i(t)=k+S t^{1 / 2}-C t
$$

where $C$ is a constant for curve-fitting purposes. The extra term is often regarded as empirical, but fully justified in unsaturated flow theory [16].

More recently, marked deviations from linearity between $i$ and $t^{1 / 2}$ have been observed in autoclaved aerated concrete [21] and vuggy limestone [22] where there is a bimodal pore size distribution comprised of fine matrix pores and large coarse pores. In these studies, the authors attributed this abnormal imbibition behaviour to the presence of large pores which contribute substantially to the total porosity but provide little capillary action and do not conform to the standard $t^{1 / 2}$ sorptivity. The abnormal imbibition data were analysed by fitting two linear components corresponding to large pores and fine matrix pores using Sharp Front (SF) analysis [17, 23], assuming the total absorption is made up of contributions from the filling of the fine and large pores. The anomalous sorptivity and marked deviations were explained well by their model. However, this model cannot be applied without additional structural information in support of its interpretation.

Many of the earlier measurements of sorptivity in building materials were carried out by traditional gravimetric measurements where the mass of the sample is determined at fixed time intervals [13, 14, 16]. These works have demonstrated that useful information can be obtained from bulk sample monitoring techniques. The main disadvantage of the gravimetric measurement is that perturbation of the sample is necessary. Spatial resolution can be achieved in gravimetric studies only through destructive analysis, i.e. cutting the sample into slices, and the spatial resolution is very low so details 
of the water transport may be missed, especially in materials with a heterogeneous structure. Thus, it is essential to develop more sophisticated experimental procedures for measuring the dynamic water uptake in porous materials. Numerous methods have been proposed that provide a spatial distribution, or profile, of the water in the sample over time. These profile measurements should be non-destructive, rapid, quantitative, and offer appropriate spatial resolution. Suitable techniques, including gamma ray attenuation [24-28], neutron radiography [29-33], positron emission tomography [34], time domain reflectometry [35], X-ray absorption [36-38], and nuclear magnetic resonance (NMR) / magnetic resonance imaging [15, 39-42], have been used by researchers to measure water content in many building materials. Of these methods, MRI is particularly useful since it measures directly the mobile water content within the sample, although chemically 'bound' water cannot be detected with standard MRI techniques. However, measuring 'bound' water is not required to study the macroscopic hydraulic properties of porous building materials. Over the past decades, MRI techniques have proven to be extremely reliable for visualising the water distribution and quantifying the dynamic transport of water in porous building materials $[9,10,15,39-47]$.

In this article, three different gypsum samples are investigated: one non-aerated gypsum sample as a reference and two aerated gypsum samples produced at different volumetric air fractions. We apply a standard MRI one-dimensional spin-echo imaging sequence [48] to measure the water content profiles during capillary absorption into these gypsum samples in a quantitative and non-destructive manner. $\mathrm{SF}$ analysis is used to describe the wetting processes occurring in the reference and aerated gypsum samples, and we use this analysis to relate the sorption characteristics of these materials to their pore structure.

\section{Unsaturated Flow Theory}

Assuming that the effect of gravity is neglected, the problem of the isothermal absorption of water by a non-reactive porous building material is usually formulated by the so-called extended Darcy equation

$$
q=-K(\theta) \nabla \psi(\theta)
$$

where $q$ is the volumetric flow per unit area, $K(\theta)$ is the hydraulic conductivity and $\psi(\theta)$ is the capillary potential. Since both $\mathrm{K}$ and $\psi$ are functions of the volumetric water content $\theta$, (3) can be expressed as

$$
q=-D(\theta) \nabla \theta,
$$

where $\nabla \theta$ is the gradient in water content and $D(\theta)=K(\theta)[\mathrm{d} \psi(\theta) / \mathrm{d} \theta]$ is the hydraulic diffusivity of water within the porous material. By combining (4) with the requirement of continuity, the water movement in a partially saturated material is described by the following diffusion equation [6-10] 


$$
\frac{\partial \theta}{\partial t}=\nabla \cdot[D(\theta) \nabla(\theta)]
$$

However, the variations of $D(\theta)$ are usually nonlinear for most porous materials so (5) has no general analytic solution. For one-dimensional water absorption, with $\theta=\theta_{0}$ at $x>0$ at $t=0$ (an initial uniform distribution of water content) and $\theta=\theta_{1}$ at $x=0$ at $t>0, \theta$ can be expressed in terms of the single Boltzmann variable [7, 8],

$$
\lambda(\theta)=\frac{x}{t^{1 / 2}}
$$

where $t$ is elapsed time and $x$ is the distance of the wetting front from the inlet face.

By application of the Boltzmann variable $\lambda$, and provided that $D(\theta)$ is a function of $\theta$ only, (5) can be simplified to the following ordinary differential equation

$$
\frac{\lambda}{2} \frac{\mathrm{d} \theta}{\mathrm{d} \lambda}+\frac{\mathrm{d}}{\mathrm{d} \lambda}\left[D(\theta) \frac{\mathrm{d} \theta}{\mathrm{d} \lambda}\right]=0
$$

with the conditions $\theta=\theta_{1}$ at $\lambda=0$ and $\theta=\theta_{0}$ at $\lambda \rightarrow \infty$.

Equation (7), under these boundary conditions, has only one solution so the wetting front is expected to progress as $t^{1 / 2}$. The cumulative water absorption $i$ at any time $t$ is given by

$$
i=\int_{\theta_{0}}^{\theta_{1}} x \mathrm{~d} \theta=t^{1 / 2} \int_{\theta_{0}}^{\theta_{1}} \lambda(\theta) \mathrm{d} \theta
$$

where $i$ is the cumulative volume absorbed per unit area of the inlet face. This integration is defined by Philip [8] as the sorptivity $S$ such that

$$
S=\int_{\theta_{0}}^{\theta_{1}} \lambda(\theta) \mathrm{d} \theta
$$

and

$$
i=S t^{1 / 2}
$$

$\lambda(\theta)$ is the solution of (5) for a one-dimensional semi-infinite system, subject to a boundary condition $\theta=\theta_{1}$ at $x=0$ and an initial condition $\theta=\theta_{0}$ for $x>0, t=0$ (uniform initial water content). In practice, (10) is often re-written to give (1) by introducing a constant $k$, representing small a non-zero intercept for curve-fitting purposes [16, 20]. Using (1), the sorptivity $S$ of the material can therefore be 
obtained from a plot of $i$ versus $t^{1 / 2}$ using a linear best-fit regression. The linearity of the relationship is often checked using the correlation coefficient of linear regression. In building physics, if the value of the correlation coefficient is $r<0.98$ (or $r^{2}<0.96$ ) the relation is considered not to be linear and the sorptivity of the specimen should not be determined from those data [49].

\section{Materials and Methods}

The reference gypsum sample was prepared by mixing $\beta$-form plaster powder (from desulphogypsum) with water at a $w / p=0.7$ (by mass). The aerated gypsum samples were prepared by an air-entraining method. Their structure is formed by introducing foam, produced by aerating a foaming agent (sodium lauryl sulphate), into the wet plaster slurry, of $w / p=0.7$, using a foam generator. Two aerated gypsum samples were made at theoretical volumetric air fractions of $48 \%$ and $65 \%$, which we refer to as samples A and B, respectively.

The wet gypsum slurries were introduced into moulds to produce cylindrical samples of size $24 \mathrm{~mm} \times$ $48 \mathrm{~mm}$ (diameter $\times$ length). The samples were allowed to hydrate for 2 hours, then taken out of the mould and dried in an oven at $40{ }^{\circ} \mathrm{C}$ until they reached a constant mass, at which point it was assumed that all the mobile water had evaporated. The details of the basic properties of the three different gypsum samples investigated in this paper are presented in table 1 . The total porosity increased as the volumetric air fraction increased; the dry density and the compressive strength were significantly reduced by increasing the volumetric air fraction in the gypsum plaster.

Table 1. The basic properties of the gypsum samples investigated. The total porosity was determined by helium porosimetry using an ErgoTech (Conwy, UK) digital modular helium expansion volume meter. The compressive strength tests were carried out on a ZWICK-Z020 material test machine.

\begin{tabular}{ccccc}
\hline sample & $\begin{array}{c}\text { volumetric air } \\
\text { fraction } / \%\end{array}$ & $\begin{array}{c}\text { total porosity } \\
/ \%\end{array}$ & $\begin{array}{c}\text { dry density } \\
/ \mathrm{kg} \mathrm{m}^{-3}\end{array}$ & $\begin{array}{c}\text { compressive peak } \\
\text { stress / } \mathrm{mm}^{-2}\end{array}$ \\
\hline Reference & 0 & $50.3 \pm 1.1$ & $1154 \pm 16$ & $14.2 \pm 1.4$ \\
A & 48 & $70.1 \pm 0.6$ & $704 \pm 14$ & $5.4 \pm 0.7$ \\
B & 65 & $78.6 \pm 0.3$ & $490 \pm 16$ & $2.0 \pm 0.4$ \\
\hline
\end{tabular}

Water absorption studies were carried out using the geometry shown in figure 1. Following drying of the samples as described earlier, the vertical sides of the samples were sealed with strips of vinyl tape to ensure that the water uptake through the sample was one-dimensional. The upper face of the sample was not sealed allowing the air to escape ahead of the advancing water wetting front in order to avoid any back-pressure. During the experiment, the water level is kept constant.

[figure 1 about here.] 
The water content profiles obtained during capillary water ingress were acquired using a Bruker AV spectrometer and a $2 \mathrm{~T}$ horizontal-bore imaging magnet, corresponding to a resonant frequency of 85 $\mathrm{MHz}$ for ${ }^{1} \mathrm{H}$. The water absorption apparatus (encompassing the gypsum sample and reservoir) was positioned in the centre of the radio frequency (rf) coil. The orientation is such that the gypsum sample of height $48 \mathrm{~mm}$ stands vertically within the horizontal bird-cage rf coil of diameter $60 \mathrm{~mm}$. Imbibition is therefore observed on the vertical $y$-axis whilst the static magnetic field is aligned along the horizontal $z$-axis. Excitation pulse lengths of duration $t_{90}=18 \mu \mathrm{s}$ and $t_{180}=36 \mu \mathrm{s}$, corresponding to tip angles of $90^{\circ}$ and $180^{\circ}$, respectively, were typical. A standard one-dimensional spin-echo imaging sequence [48] was employed to obtain profiles with 256 pixels along the vertical length $l$ of the sample at a resolution of $\sim 200 \mu \mathrm{m}$ per pixel. The echo time is $\tau=2 \mathrm{~ms}$, and profiles were acquired at a rate of one per minute.

To determine the NMR signal intensity corresponding to complete saturation, the samples were vacuum-saturated under water. A calibration profile was acquired on each water-saturated sample to compare against the profiles acquired during capillary absorption. For the pore structure characterisation, transverse relaxation time $\left(T_{2}\right)$ measurements were performed on these saturated samples using a single-shot Carr-Purcell Meiboom-Gill (CPMG) sequence [50, 51]. CPMG echo trains were acquired with 1024 echoes, separated in time by $2 \tau=800 \mu \mathrm{s}$, with 2 repeat scans to eliminate any baseline offset. The CPMG decays were converted into distributions of relaxation times using a numerical inversion. This is an inherently ill-posed problem and requires some constraints to produce a stable solution. Here we use Tikhonov regularisation $[52,53]$ with the smoothing parameter determined by the Generalized Cross Validation (GCV) method [54, 55]. In addition, scanning electron microscopy (SEM) images were acquired to analyse the pore structure. These images were obtained using a bench-top Hitachi TM-1000 SEM.

The gravimetric test was carried out separately by allowing one surface of the sample to be in contact with the water reservoir. The weight gain of the sample was recorded at fixed time intervals and was recorded over a total time of 60 minutes. At each measurement, the timing device was stopped, the surface water was removed with a dampened cloth, and the sample weight was determined. The sample was then returned back to its place in the testing frame and the gravimetric uptake continued. The time of each weighing operation did not exceed $20 \mathrm{~s}$.

\section{Results and Discussion}

Prior to performing the water absorption experiments, the microstructure of the gypsum samples was analysed using SEM and NMR techniques. The same techniques have been used previously to characterize other gypsum products and hydration processes [56, 57]. The SEM microstructures of the three different samples are shown in figure 2. In the reference sample, figure 2(a), a homogeneous 
structure of fine matrix pores generated by the formation of gypsum crystals is seen as expected. Introducing a volumetric air fraction in samples A and B, figure 2(b) and (c), respectively, results in the microstructure becoming more heterogeneous. These aerated gypsum plasters consist of large air voids interspersed in the fine matrix pore network. The air voids are seen to be roughly spherical cavities, created as bubbles by the foam in the wet slurry. It is also seen that the total volume associated with the air voids as well as their individual size increase with an increase in the volumetric air fraction. For each sample, 3 different SEM images, each containing approximately 100 pores and air voids, were analysed. Approximate average pore sizes were obtained by counting the number of pixels across the pores in each image. In this way, the mean pore radius of the fine matrix pores was estimated as $R \approx 20 \mu \mathrm{m}$ whereas the mean radius of air voids was estimated as $R \approx 200 \mu \mathrm{m}$ in sample A and $300 \mu \mathrm{m}$ in sample B.

[figure 2 about here.]

The characteristic pore size distributions (PSDs) of the gypsum samples, determined from NMR $T_{2}$ relaxation distributions, are shown in figure 3 . The $T_{2}$ axis was rescaled into a pore size by estimating a surface relaxivity of $\rho \approx 3.6 \times 10^{-4} \mathrm{~m} \mathrm{~s}^{-1}$. This relaxivity value was based on the average $S / V$ ratio of the pore structure determined from independent NMR diffusometry experiments and assuming the pores are spherical. Additional details of the process are given in $[58,59]$. We emphasis that this pore length-scale is an estimate only of the actual PSD, presented for the convenience of the reader. In figure 3(a), it is seen that the reference sample exhibits two distinct peaks in the pore size distribution. These two peaks correspond to the fine matrix pores as seen in figure 2(a). A matrix pore network characterized by two relaxation time peaks was observed previously in other gypsum-based materials $[56,60]$. The dominant peak is centred on a pore radius $R \approx 20 \mu \mathrm{m}$, which is consistent with the mean pore size obtained from the SEM images. Figure 3(b) and (c) show the PSDs of the aerated gypsum samples $\mathrm{A}$ and $\mathrm{B}$, respectively. Here, the two peaks corresponding to the matrix pores remain prominent, but an additional peak is seen corresponding to the large air voids. The peaks corresponding to the large air voids are centred on a pore radius $R \approx 200 \mu \mathrm{m}$ and $300 \mu \mathrm{m}$ for samples $\mathrm{A}$ and $\mathrm{B}$, respectively, which is in agreement with the SEM images.

[figure 3 about here.]

The experimental water imbibition data (expressed as $i$ versus $t^{1 / 2}$ ) obtained during capillary imbibition of water into the reference sample is shown in figure 4, where the cumulative water absorption $i$ is obtained gravimetrically as reported in [49],

$$
i=\frac{\Delta m}{a \rho}
$$


where $\Delta m$ is the change in mass, $a$ is the sample cross-sectional area, and $\rho$ is the density of water. The cumulative infiltration $i$ varies linearly with $t^{1 / 2}$ as expected, and therefore the sorptivity can be derived directly from the plot using (1). The sorptivity $S$ into the reference sample is $1.50 \pm 0.12$ $\mathrm{mm} \min ^{-1 / 2}$, which is within the range expected for a gypsum plaster [10]. The linearity of the relationship is assessed from the value of the correlation coefficient of linear regression. In this case, the correlation coefficient $r=0.998$. The slower increase of water content after 50 minutes has been attributed to a dissolution and removal of air that is entrapped within the sample after the wetting front has reached the end of the sample [61].

[figure 4 about here.]

The MRI water content profiles measured at different times during capillary imbibition of water into the reference sample are shown in figure 5(a). Profiles were acquired from 2 to 60 minutes at a rate of one per minute; only every third profile has been plotted in figure 5 for clarity. The lower $10 \mathrm{~mm}$ of the profile are ignored in the analysis as this portion of the sample was submerged at all times, preventing accurate determination of the water ingress. The reservoir was large (in the horizontal direction) so the reduction in meniscus height over the course of the experiment was small compared to the spatial resolution of the profile. The NMR magnetisation, and hence the water content, at the inlet face was scaled to the measured capillary water content $\theta_{\text {cap }}=0.272$, which is the maximum water content attained by submerging the sample in water under atmospheric conditions.

The direction of water movement is from left to right, as indicated by the horizontal arrow. As soon as the base of the sample is brought into contact with the water reservoir, the wetting front moves towards the top of the sample. Once the wetting front has reached the end of the sample, as seen in the profile highlighted by the thick line in figure 5(a), there is a further increase in water content, indicated by the vertical arrow. This is consistent with the slow increase in water content, observed gravimetrically, after 50 minutes; see figure 4 . This behaviour has been attributed previously to dissolution and removal of air [61]. Here, it is clear from the MRI profiles that the leading edge of the wetting front reaches the end of the sample at $t=50$ minutes. Capillary imbibition continues to draw water into the empty pores at the top of the sample until the maximum saturation achievable via this mechanism is attained. However, since the wetting front is now stationary, the water uptake rate is no longer governed by Fickian diffusion. This final stage of imbibition results in the reduction in rate of water ingress observed in the gravimetric data.

Following (8), the wetting front advances along the length of the sample as a function of $t^{1 / 2}$. Plotted against the Boltzmann variable $\lambda$ in figure $5(\mathrm{~b})$, the observed water profiles collapse on to a master curve of water content $\theta(\lambda)$. This indicates that the moisture diffusivity does not depend on the position in the sample and supports the modelling of the water transport during capillary water 
absorption by (5), with the boundary conditions $\theta=\theta_{1}$ at $x=0, t>0$ and $\theta=\theta_{0}$ for $x>0, t=0$. Under these conditions, $\theta_{1}=\theta_{\text {cap }}$ and $\theta_{0}=0$ for the initially dry sample.

[figure 5 about here.]

According to (8), the area under any of the individual profiles gives a direct measure of the cumulative water infiltration. The cumulative infiltration $i$ is plotted as a function of $t^{1 / 2}$ in figure $6(\mathrm{a})$. The sorptivity of the reference sample is $S=1.52 \pm 0.08 \mathrm{~mm} \mathrm{~min}^{-1 / 2}$ with a correlation coefficient $r=$ 0.999 . This sorptivity value is in good agreement with $S=1.50 \pm 0.12 \mathrm{~mm} \mathrm{~min}^{-1 / 2}$ obtained from figure 4 using the gravimetric measurement. The same procedures were repeated three times on the representative sample in order to check the reproducibility of the sorptivity. Despite the repeated wetting and drying processes, no evidence of systematic changes in sorptivity was observed.

The MRI water content profiles allow for the precise tracking of the position of the wetting front. The position of the wetting front $x_{\mathrm{wf}}$ is taken at the point where the profile reaches $\theta=0$. The wetting front penetration $x_{\mathrm{wf}}$ as a function of $t^{1 / 2}$ is plotted in figure 6(b) for the reference sample. The rate of advance is $\mathrm{d} x_{\mathrm{wf}} / \mathrm{d} t^{1 / 2}=\mathrm{S} / \bar{\theta}$ where $\bar{\theta}$ is the average water content of the wetted region [15]. Here, $S$ $=1.52 \mathrm{~mm} \mathrm{~min}^{-1 / 2}$ and $\mathrm{d} x_{\mathrm{wf}} / \mathrm{d} t^{1 / 2}=7.11 \mathrm{~mm} \mathrm{~min}^{-1 / 2}$ so $\bar{\theta}=0.214$, which is equivalent to $74 \%$ of the saturated water content $\theta_{\text {sat }}=0.29$. Incomplete saturation is confirmed by comparison of the final profile in figure $5(\mathrm{a})$ with the profile obtained from the vacuum-saturated sample, as indicated by dashed line in figure 5(a). Water is not imbibing into all the pores and this is most evident between $x=$ 30 and $50 \mathrm{~mm}$ whereas almost complete saturation of the sample is achieved at long times for $x<30$ $\mathrm{mm}$ in figure 5(a). The failure of the wetting liquid (water) to displace the non-wetting gas (air) at the end of the sample is typical of a capillary end-effect.

[figure 6 about here.]

Now we consider the aerated samples that have a more complicated structure containing a significant volume of air voids. The gravimetric imbibition data, obtained during capillary imbibition of water into the aerated gypsum samples, is shown in figure 7. Although the data appear to be non-linear, we still choose to fit the relationship between the cumulative infiltration $i$ and $t^{1 / 2}$ with a straight line regression. The overall sorptivity into sample A is $S=2.89 \pm 0.09 \mathrm{~mm} \mathrm{~min}^{-1 / 2}$ with the correlation coefficient $r=0.994$, whereas, for the sample B, the overall sorptivity is $S=2.66 \pm 0.11 \mathrm{~mm} \mathrm{~min}^{-1 / 2}$ with the correlation coefficient $r=0.994$. Since $r>0.98$ in both samples it would be reasonable [49], lacking prior knowledge of the pore structure, to attribute these sorptivity values to a single wetting front moving through the sample.

[figure 7 about here.] 
The MRI water content profiles determined during capillary water absorption into the aerated gypsum samples A and B are shown in figure 8(a) and (b), respectively. For the aerated samples, abnormal absorption behaviour is clearly seen. The wetting front is no longer well defined and there are distinct gradient variations (steps) in the water content profiles. This suggests that there is more than one wetting front advancing through the aerated structure, each with a different sorptivity. The capillary water content for sample A is $\theta_{\text {cap }}=0.460$. This is nearly double that of the reference sample where $\theta_{\text {cap }}=0.272$ due to the increased porosity. However, it is important to note that for sample $\mathrm{B}$, even though the total porosity is increased significantly accompanied by a reduction in density (see table 1), the capillary water content $\theta_{\text {cap }}=0.482$ is only slightly higher than for sample A.

[figure 8 about here.]

It is obvious that the distinct steps in the water content profiles are a result of the modification to the pore structure by large air voids. The fast absorption corresponds to imbibition, predominantly, into the fine matrix pores where the capillary pressures are large and prevent redistribution by gravitational force. Here, we offer the conjecture that the continuous, interconnected pore network containing small matrix pores and large air voids actually behaves as two distinct parallel networks. A large capillary pressure is generated through a series of connected matrix pores, resulting in rapid imbibition: this corresponds to the fast moving wetting front. The modified structure - a series of air voids linked by matrix pores - fills slowly once the surrounding network of matrix-only pores has been saturated. This is a rate limiting step controlled by the low capillary pressures generated in the air voids. The MRI profiles indicate that these air voids fill only partially, and progress of the water through the modified network may occur as a result of the formation of water films inside the air voids. Additional studies, beyond the scope of this paper, will be required to elucidate the actual pore structure and interplay of these parallel networks. A schematic of our proposed water imbibition process is shown in figure 9. If the matrix pores were not present, the capillary pressures generated by the air voids would be insufficient to overcome gravity. Therefore, our assumption that the filling of the air voids is dependent on water transport through the adjacent matrix pores is not unreasonable. Thus the combination of large air voids with a low capillary pressure and fine matrix pores with a high capillary pressure result in a non-uniform progression of the wetting front.

[figure 9 about here.]

The plot of the cumulative infiltration, calculated from the MRI water content profiles, for samples A and $B$ are shown in figure $8(\mathrm{c})$ and (d), respectively. There is a systematic underlying curvature in the data due to the presence of two wetting fronts. It is interesting to note that a straight line regression still provides a reasonable fit to this data. The larger deviation observed between the data and the 
fitted line at short times $\left(t^{1 / 2}<2 \mathrm{~min}^{1 / 2}\right)$ can be attributed to the relatively low temporal resolution of the MRI acquisition compared to the speed of the initial imbibition. The overall sorptivity into sample A is $S=3.02 \pm 0.11 \mathrm{~mm} \mathrm{~min}^{-1 / 2}$ with the correlation coefficient $r=0.998$, whereas for sample B the overall sorptivity is $S=2.70 \pm 0.09 \mathrm{~mm} \mathrm{~min}^{-1 / 2}$ with the correlation coefficient $r=0.997$. These sorptivity values obtained from the MRI profiles are consistent with those obtained from the gravimetric measurements; see figure 7. It is seen that the overall water absorption into sample B is slower than into sample A, indicating a reduction in the overall effective capillary pressure in sample $\mathrm{B}$ due to the increase in the number and volume of air voids. Notwithstanding, sample B absorbs more water than sample A due to the increased voidage; the maximum saturation just requires longer to be attained. The anomalous wetting front behaviour is obvious immediately on examination of the MRI water content profiles, but not obvious from the overall cumulative infiltration plots shown in figure 7 or 8 . Therefore, unlike analysis of the gravimetric data, the MRI profiles provide a clear indication of the heterogeneous pore structure without the need for further information.

To understand the complex wetting processes occurring in the aerated gypsum samples, the MRI water content profiles were further analysed by treating them as the sum of two separate absorption processes. Thus, the water content profiles were divided into two regions based on the distinct curvature in the water content profiles, as indicated by the horizontal dotted lines in figure 8 . In figure 8(a), the water content profiles were divided into two regions characterized by $\theta<0.19$ and $\theta>0.19$. The lower region of the water content profiles $(\theta<0.19)$ is assigned to water imbibition, predominantly, into the matrix pores. The upper region of the water content profiles $(0.19<\theta<0.46)$ is assigned to imbibition into the pore structure modified by air voids. Likewise, in figure 8(b), the lower region of the water content profiles $(\theta<0.21)$ is assigned to water imbibition into the matrix pores and the upper region of the water content profiles $(0.21<\theta<0.482)$ is assigned to imbibition into the modified structure with air voids. Considering the upper and lower regions separately, new cumulative infiltration values were obtained as shown in figure 10 for the (a) lower and (b) upper regions of water content profiles from sample A, and the (c) lower and (d) upper regions of water content profiles from sample B. Linear fits have been applied to the cumulative infiltration data in each case and these fits provide improved correlation coefficients. The corresponding sorptivity values are collated in table 2. In general, it would not be valid to apply the linear fit described by equation (1) to these long time data in figure 10(a) and (c) since a large constant $k$ would then be obtained. However, in this case we make the assumption that the two wetting fronts behave independently and the Boltzmann transform can be applied to the slow moving front even after the fast moving front has reached the end of the sample. This assumption is supported by the data collapse onto a master curve shown in figure 5(b). 
Table 2. Sorptivity values of the aerated gypsum samples A and B determined from figure 10 . The wetting front reaches the top surface of the sample at $t=14$ and $18 \min$ for samples $\mathrm{A}$ and $\mathrm{B}$, respectively.

\begin{tabular}{|c|c|c|c|c|c|}
\hline \multicolumn{4}{|c|}{ sample A } & \multicolumn{2}{|c|}{ sample B } \\
\hline $\begin{array}{l}\text { time } \\
/ \text { min }\end{array}$ & \multicolumn{2}{|c|}{ sorptivity / $\mathrm{mm} \mathrm{min}^{-1 / 2}$} & $\begin{array}{l}\text { time } \\
/ \text { min }\end{array}$ & \multicolumn{2}{|c|}{ sorptivity / $\mathrm{mm} \mathrm{min}^{-1 / 2}$} \\
\hline & matrix pores & modified structure & & matrix pores & modified structure \\
\hline$t<14$ & 1.98 & 0.75 & $t<18$ & 1.83 & 0.64 \\
\hline$t>14$ & 0.19 & 2.62 & $t>18$ & 0.42 & 2.27 \\
\hline
\end{tabular}

[figure 10 about here.]

The sorptivity of the matrix pores in samples A and B are $S_{\mathrm{m}}=1.98$ and $1.83 \mathrm{~mm} \mathrm{~min}^{1 / 2}$, respectively. These values are higher than the matrix sorptivity of $S=1.52 \mathrm{~mm} \mathrm{~min}^{-1 / 2}$ in the reference sample, indicating an increase in the rate of water transport through the matrix pore network. When the wetting front has reached the end of the sample ( $t=14$ minutes for A and 18 minutes for B) the matrix sorptivity reduces considerably. This is consistent with the final stage of capillary imbibition after the wetting front has reached the end of the sample, as shown earlier (e.g. see figures 4 and 5). The initial imbibition into the modified structure with air voids occurs slowly, suggesting that, at the beginning of the water absorption process, the water imbibes preferentially into the matrix pores. However, the sorptivity of the modified structure with air voids increases significantly at longer times $(t>14$ minutes for $\mathrm{A}$ and 18 minutes for $\mathrm{B}$ ), coinciding with the matrix pore wetting front reaching the end of the sample. These larger sorptivity values are attributed not only to water imbibition into the modified structure, but also to the further filling of matrix pores as capillary imbibition continues to draw water into the empty pores at the top of the sample until the maximum saturation is reached.

To model the wetting processes occurring in aerated gypsum samples, SF analysis is applied. SF analysis is considered generally to be an appropriate method of describing water absorption processes in heterogeneous samples $[15,22,62]$ since it provides an approximate and simplified approach to modelling unsaturated capillary absorption without the need to resort to complex numerical and computational analyses. It has been shown to give good agreement with experimental results in many other applications of unsaturated capillary transport [63-66]. In the SF analysis, the wetted region is approximated by a rectangular profile (equivalent to a delta-function diffusivity) with uniform and constant water content equal to the saturation water content [17]. Here, we consider two different SF models. In the first model we assume that there is a single wetting front in the aerated structure and treat the wetted region as a rectangular profile with the sorptivity of $S=2.89 \mathrm{~mm} \mathrm{~min}^{-1 / 2}$, obtained from the gravimetric measurement. In the second model we consider the multiple wetting fronts in the aerated structure, visualized by MRI profiles, and treat the wetted region as a parallel combination of two separate rectangular profiles based on the sorptivities in table 2. A comparison of the measured MRI water content profiles in sample A with the simulated profiles from the SF models is presented 
in figure 11. In each case, the thick line indicates the water profile acquired at $t=14 \mathrm{~min}$. A selection of the MRI profiles are shown in figure 11(a), repeated from figure 8(a). The simulated water content profiles obtained using the first model, with a single sorptivity of $S=2.89 \mathrm{~mm} \mathrm{~min}^{-1 / 2}$ and a capillary water content of $\theta_{\text {cap }}=0.460$, are shown in figure 11(b); it is seen that they do not represent the measured profile well. Figure 11(c) shows the water content profiles modelled with separate sorptivity values and relative capillary water contents for the matrix pores and modified structure with air voids (see table 2). The shape of the simulated profile in figure 11(c), being a sum of two absorption processes, is a much better representation of the measured MRI profile than the simulated one component profile in figure 11(b). This comparison is confirmed in figure 12, where the progress of the wetting front position $x_{\mathrm{wf}}$ is shown for the measured MRI profiles and the simulated data for sample A. The complex water imbibition behaviour into sample A is described well by the SF analysis with two separate wetting fronts.

[figure 11 about here.]

[figure 12 about here.]

Figure 13 shows the simulated profiles for the three different samples measured by MRI (see figures 5 and 8). The simulation of the reference sample using SF analysis with a single wetting front where $S=$ $1.52 \mathrm{~mm} \min ^{-1 / 2}$ and $\theta_{\text {cap }}=0.272$ are shown in figure 13(a). The water imbibition into the homogeneous reference sample is described well by this SF model. In the aerated samples, however, using a single sorptivity value obtained from the gravimetric method was not sufficient to model the complex wetting processes, as demonstrated in figure 12. Thus, in these aerated samples, the water content profiles are modelled by the SF analysis with two separate wetting fronts. The results of the simulation of the aerated samples A and B are shown in figure 13(b) and (c), respectively. The capillary water absorption properties of this material are well described as a parallel combination of fast absorption into a network of fine matrix pores and slow absorption into a modified structure with air voids introduced into the network of fine matrix pores.

[figure 13 about here.]

\section{Conclusions}

In this paper we have demonstrated the use of MRI for monitoring spontaneous water imbibition into aerated gypsum plasters. The spatially resolved profiles were analysed to achieve quantitative monitoring of the wetting front position and sorptivity. The MRI technique provided new insights into the water absorption processes that could not be obtained from conventional gravimetric sorptivity measurements. The MRI data showed that the combined presence of large air voids providing low capillary pressures and fine matrix pores providing high capillary pressures results in anomalous water absorption. The water content profiles of the aerated gypsum samples were analysed further and 
modelled as the sum of two separate absorption processes using SF analysis. It was found that a single sorptivity value obtained from the conventional gravimetric measurement was insufficient to describe the water transport in the aerated samples. However, the complex wetting was described well using a SF model with two parallel wetting fronts, each with different sorptivities obtained from the MRI water content profiles.

The introduction of large air voids into the gypsum structure created the formation of two pore networks. The rate of water penetration through the fine matrix pores was more rapid in the aerated gypsum sample than in the reference sample. However, the overall water imbibition process was delayed by the slow absorption of water into the modified pore network containing the air voids. Further increase in the volumetric air fraction used in the material production resulted in further reduction in the overall sorptivity, due to a reduced effective capillary pressure. This suggests that it might be possible to manufacture lightweight material with improved water resistance by optimising the aerated structure. In future work, we will apply this experimental method and data analysis technique to other lightweight materials (e.g. aerated concrete) to yield further understanding of the relationship between pore structure and capillary water absorption characteristics.

\section{Acknowledgements}

The authors thank Mr J. Staniland of Schlumberger Cambridge Research for the helium porosimetry measurements. K.M. Song thanks Saint-Gobain, and J. Mitchell thanks Schlumberger Cambridge Research, for financial support. 


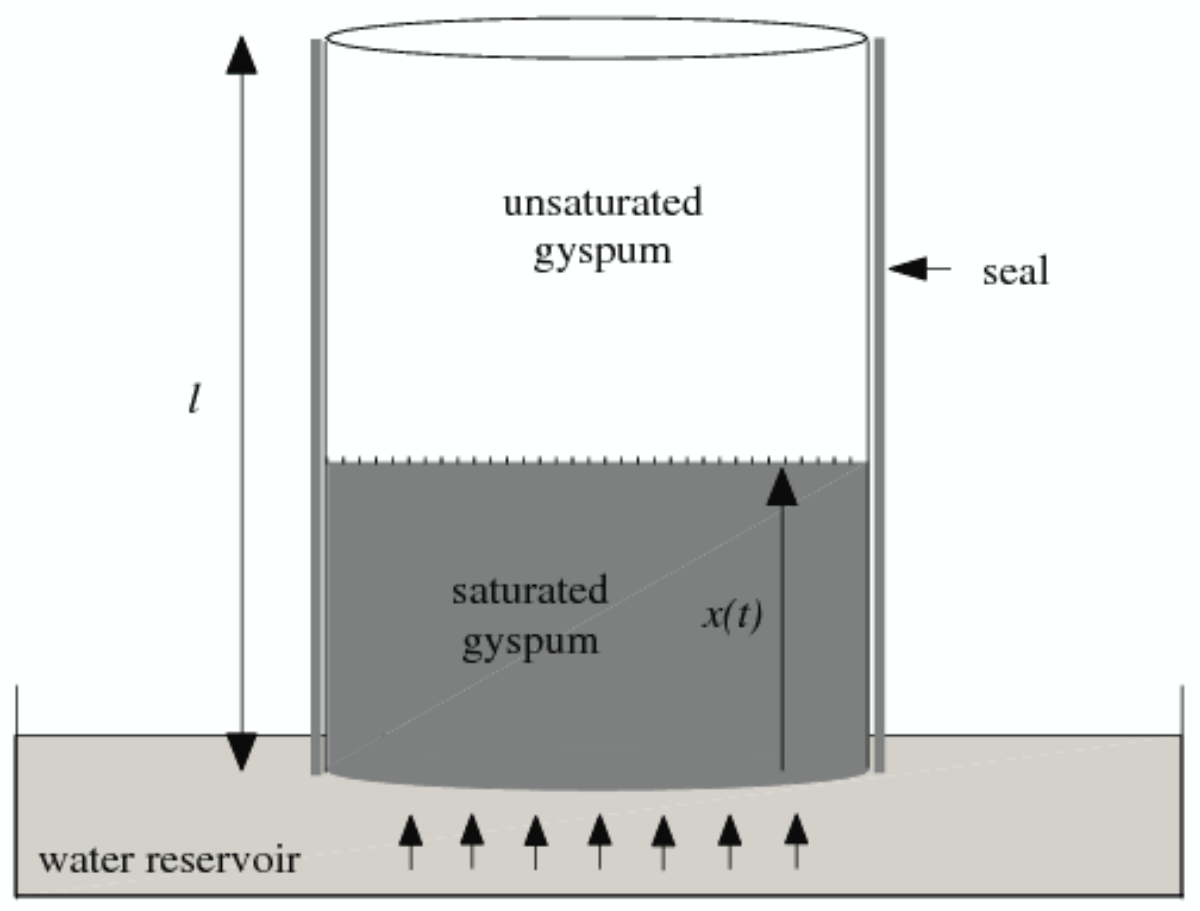

Figure 1. Schematic showing the orientation of the gypsum sample with respect to the free water reservoir, and the direction of the one-dimensional water absorption. $l$ denotes the length of the sample and $x(t)$ denotes the distance of the wetting front from the inlet face as a function of time $t$. The water reservoir volume is large compared to the gypsum sample volume and the lower $10 \mathrm{~mm}$ of the gypsum cylinder is submerged at all times. 


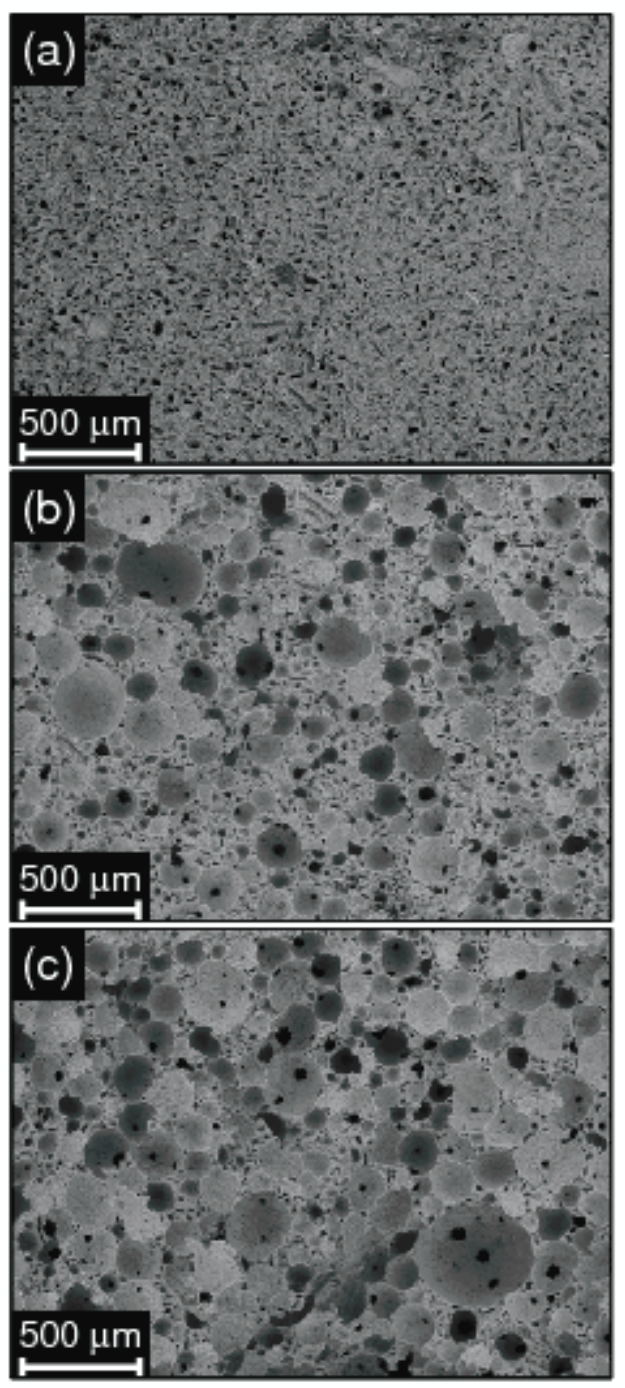

Figure 2. SEM images of (a) a reference plaster sample with fine matrix pores, and the two aerated gypsum samples: (b) sample A, and (c) sample B. A and B contain spherical air voids along with fine matrix pores. 


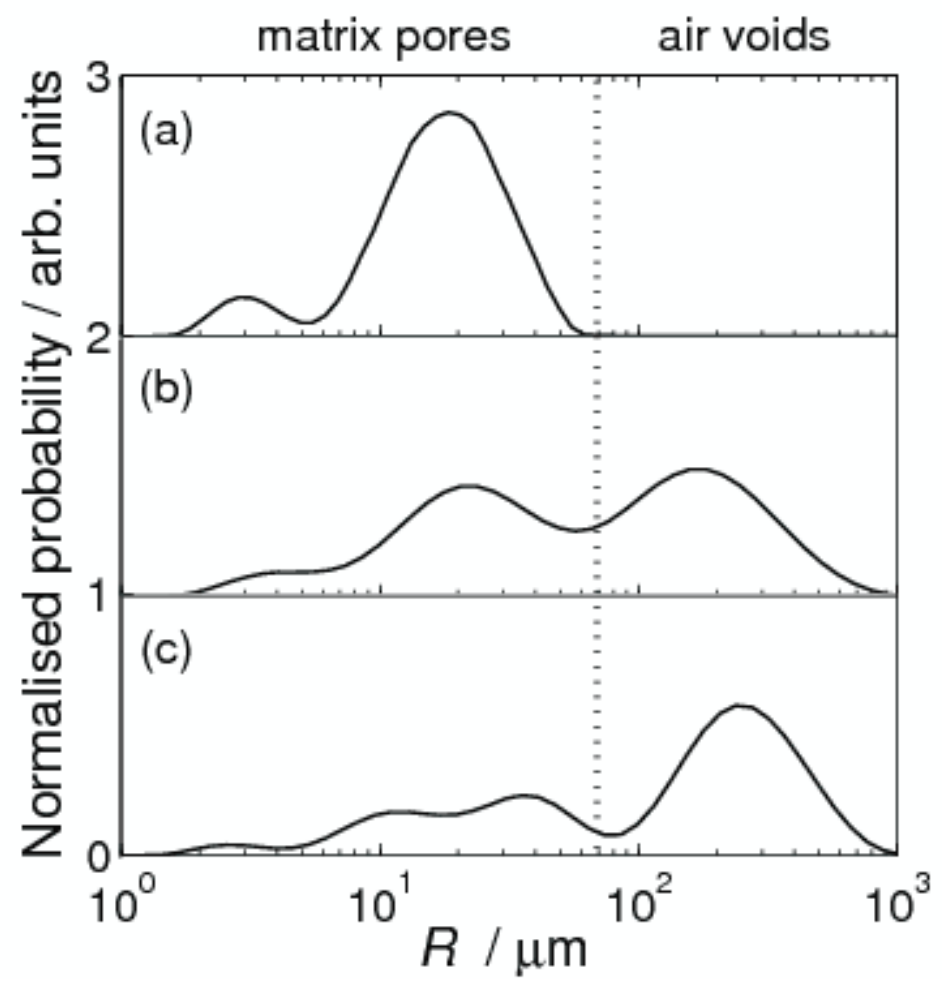

Figure 3. Pore size probability distributions, calculated from NMR $T_{2}$ relaxation time measurements, for the gypsum samples (a) reference, (b) sample A, and (c) sample B. The dotted line divides the PSDs into two regions corresponding to the matrix pores $(R<70 \mu \mathrm{m})$ and the air voids $(R>70 \mu \mathrm{m})$. 


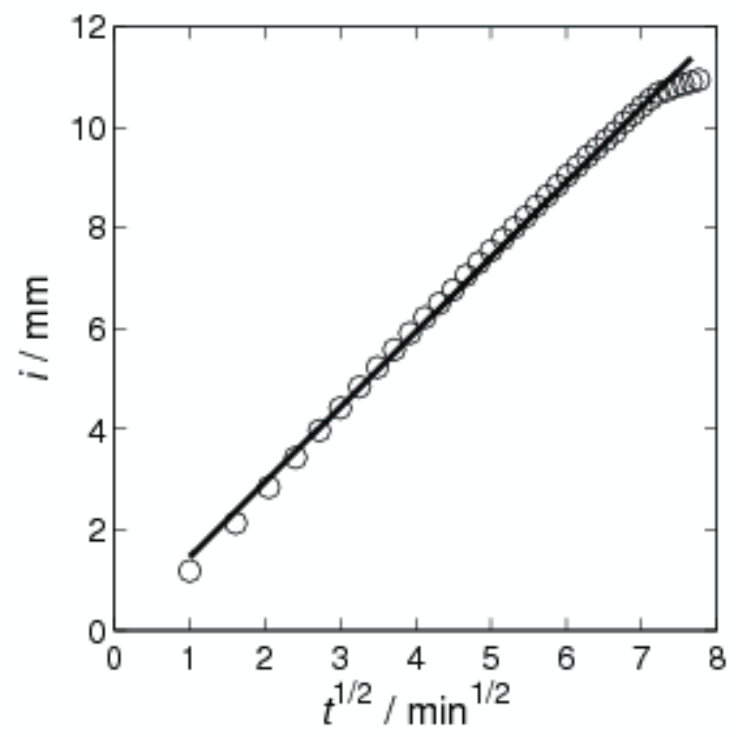

Figure 4. A plot of cumulative infiltration $i$ versus square-root of time $t$ obtained during capillary imbibition of water into the reference sample determined by the gravimetric method. The solid line is a least-squares linear fit to the data. The gradient of this line yield sorptivity $S$; in this case $S=1.50 \pm 0.15 \mathrm{~mm} \mathrm{~min}^{-1 / 2}$ with a correlation coefficient $r=0.998$. 

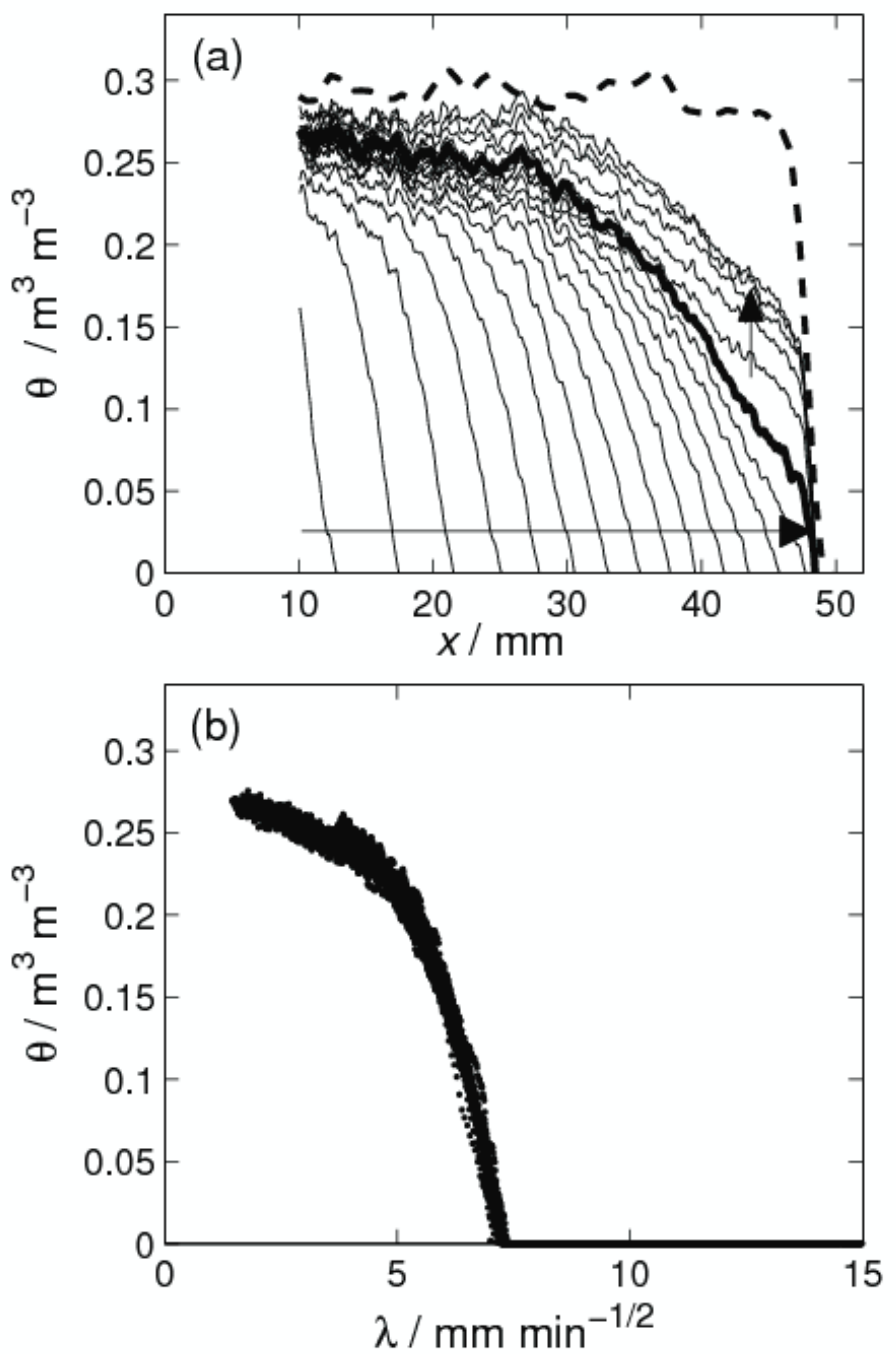

Figure 5. (a) A selection of MRI water content profiles measured at elapsed times from 2 to 60 mins, shown at regular intervals of 3 min, during water absorption into the reference sample. The thick line represents the profile at $t=50$ minutes when the wetting front has reached the top of the sample. The horizontal arrow represents the direction of water movement and the vertical arrow represents further increase in water content after the wetting front has reached the top of the sample. The dashed line represents the profile obtained from the vacuum-saturated sample. (b) A plot of water content $\theta$ as a function of Boltzmann variable $\lambda$, obtained from the water content profiles in (a); the profiles collapse on to a master profile, indicative that the wetting front progresses as $t^{1 / 2}$. 

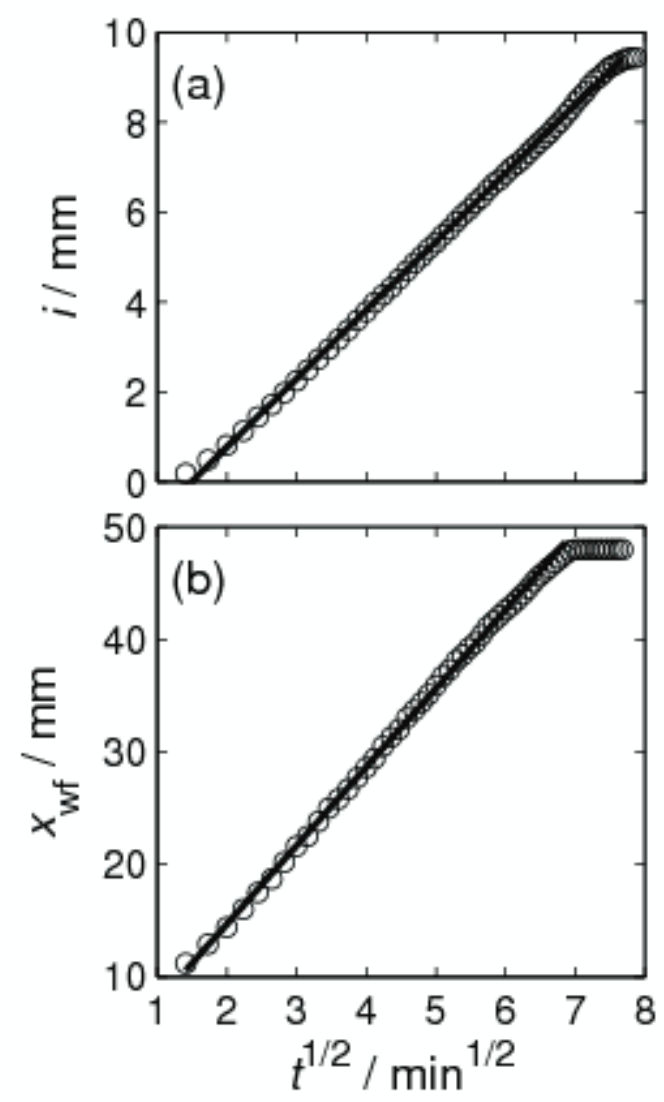

Figure 6. (a) A plot of cumulative infiltration $i$ versus square-root of time $t$, obtained from the integration of the individual MRI profiles shown in figure 5(a). The solid line is a least-squares linear fit to the data, yielding $S=1.52 \pm 0.08 \mathrm{~mm} \mathrm{~min}^{-1 / 2}$ with a correlation coefficient $r=0.999$. (b) Position of the wetting front $x_{\mathrm{wf}}$ as a function of $t^{1 / 2}$. The solid line is a least-squares linear fit to the data, where $\mathrm{d} x_{\mathrm{wf}} / \mathrm{d} t^{1 / 2}=7.11 \mathrm{~mm} \mathrm{~min}^{-1 / 2}$. 

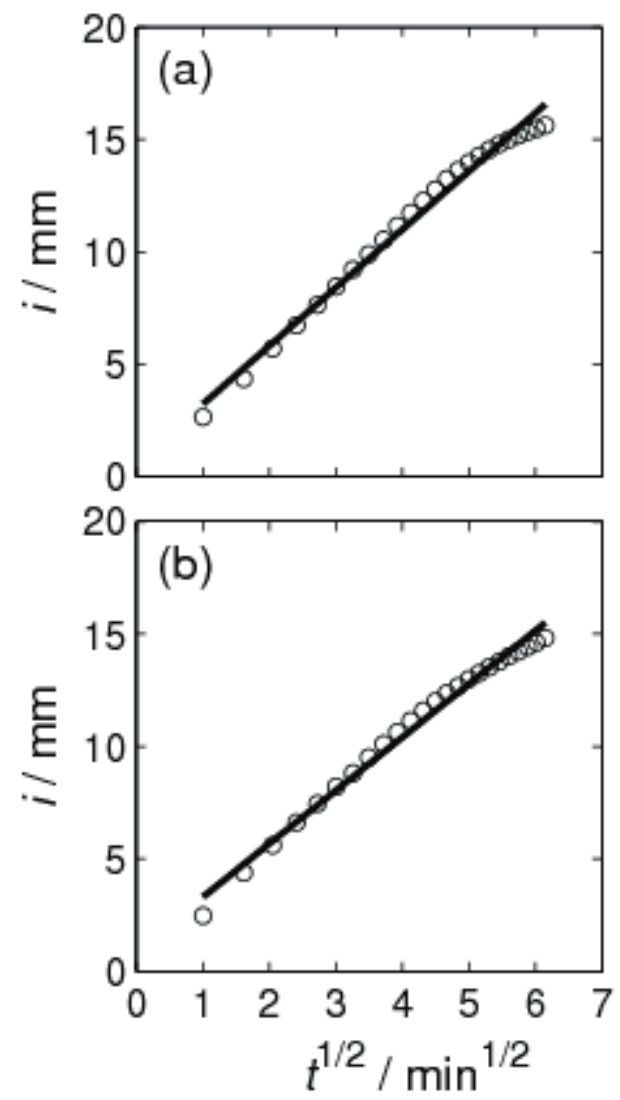

Figure 7. Plots of cumulative infiltration $i$ versus square-root of time $t$ for samples (a) A and (b) B, obtained from the gravimetric method. The solid lines are least-squares linear fits to the data, where $S=2.89 \pm 0.09 \mathrm{~mm} \mathrm{~min}^{-1 / 2}$ with a correlation coefficient $r=0.994$ for sample A, and $S=2.66 \pm$ $0.11 \mathrm{~mm} \mathrm{~min}^{-1 / 2}$ with a correlation coefficient $r=0.994$ for sample B. 

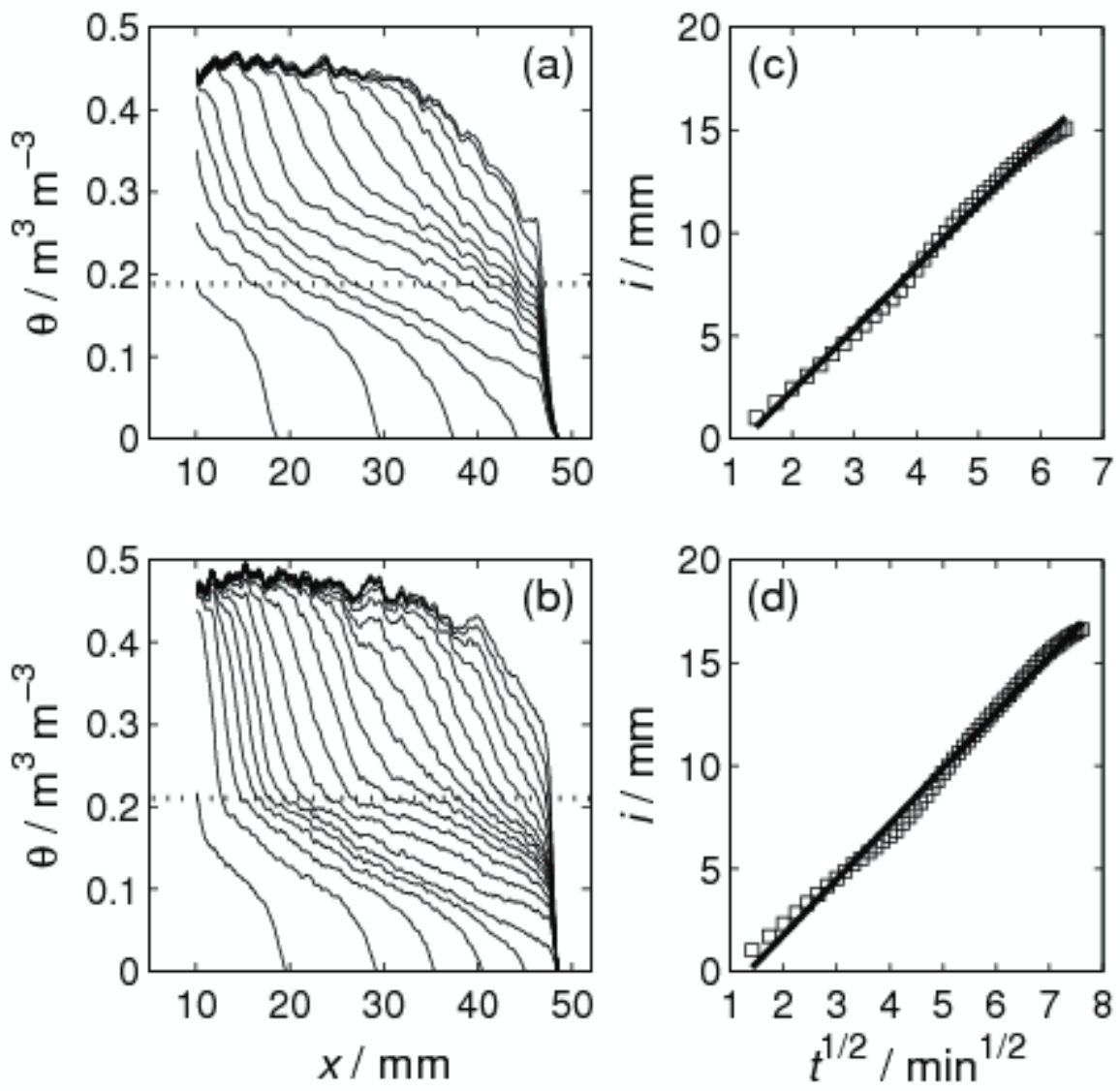

Figure 8. A selection of water content profiles acquired at regular intervals of 3 min during water absorption into samples (a) A and (b) B. The dotted lines divide the water content profiles into two different regions, which will later be associated with water absorption, predominantly, into matrix pores (lower region) and absorption into the modified structure with air voids (upper region). Plots of $i$ versus $t^{1 / 2}$ for samples (c) A and (d) B. The solid lines in (c) and (d) are least-squares linear fits to the data. 
(a)

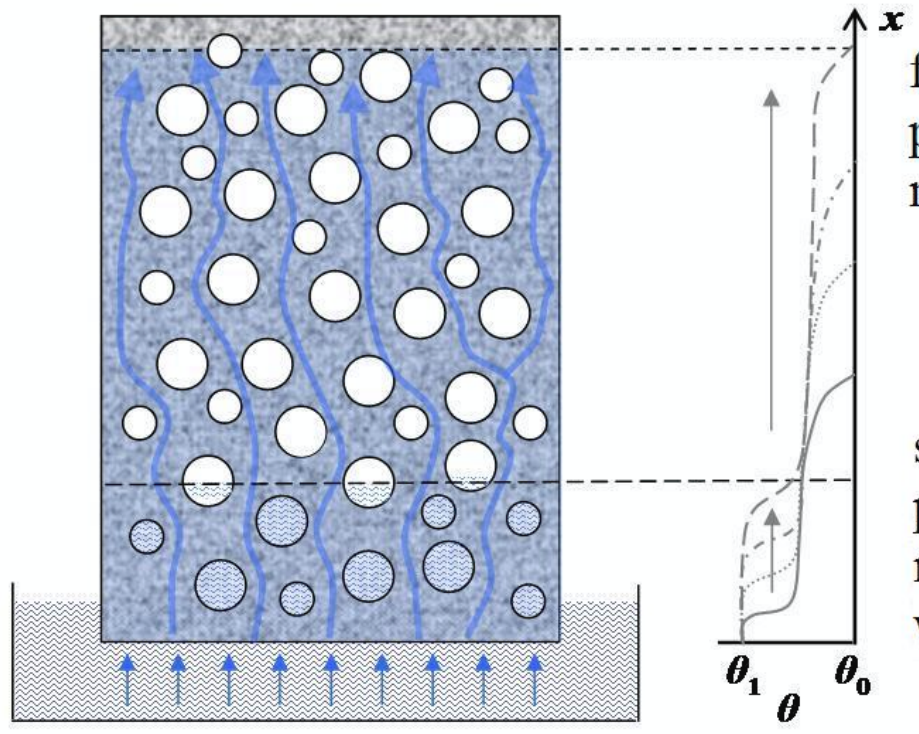

fast $t^{1 / 2}$ capillary rise

process in fine matrix porosity

slow $t^{1 / 2}$ capillary rise process through modified structure with air voids (b)

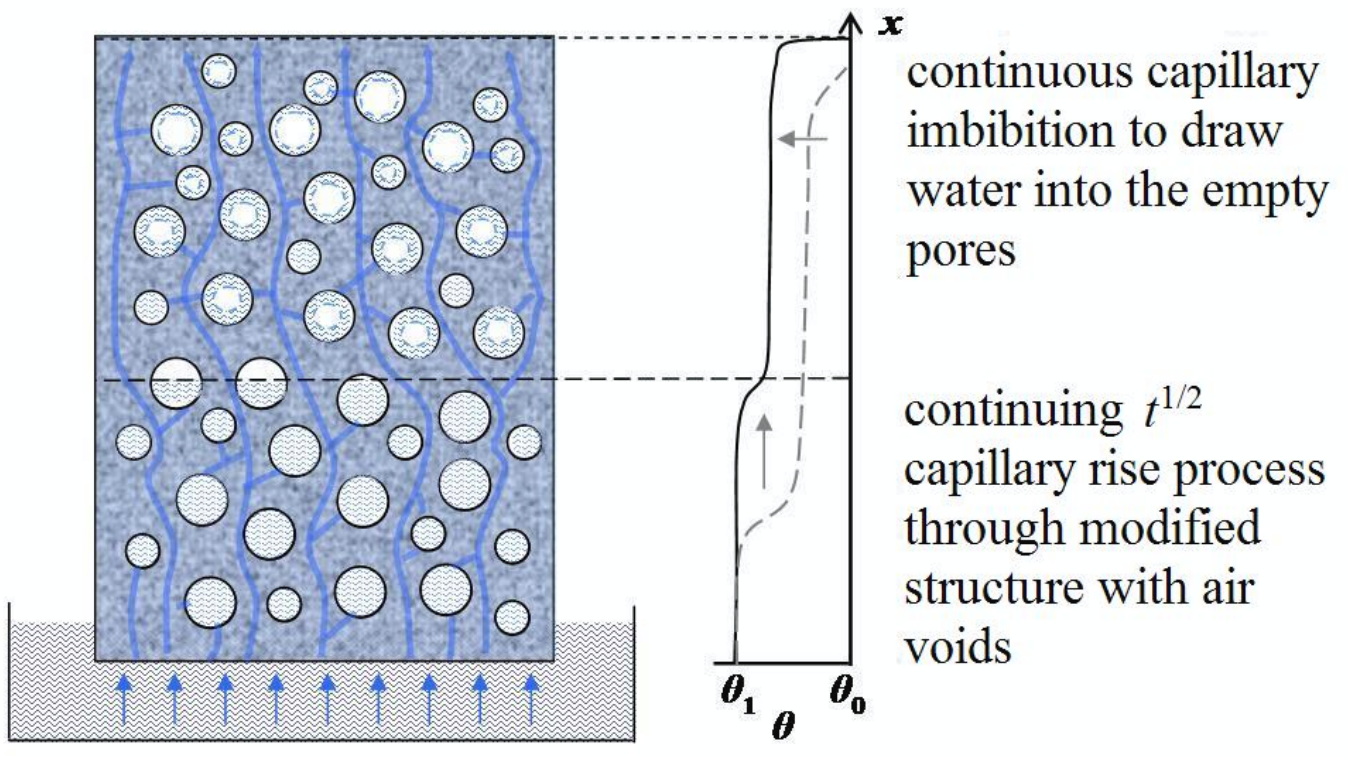

Figure 9. Illustration of possible water absorption processes in aerated gypsum; white circles represent different sizes of large air voids and continuous grey background represents fine matrix porosity. (a) Early stage absorption occurs predominantly through connected matrix pores only. This leads to rapid progress of the primary wetting front due to the high capillary pressures in these small pores. (b) Late stage absorption occurs through the modified structure as a result of filling or film formation in the large air voids connected via the matrix pores. 

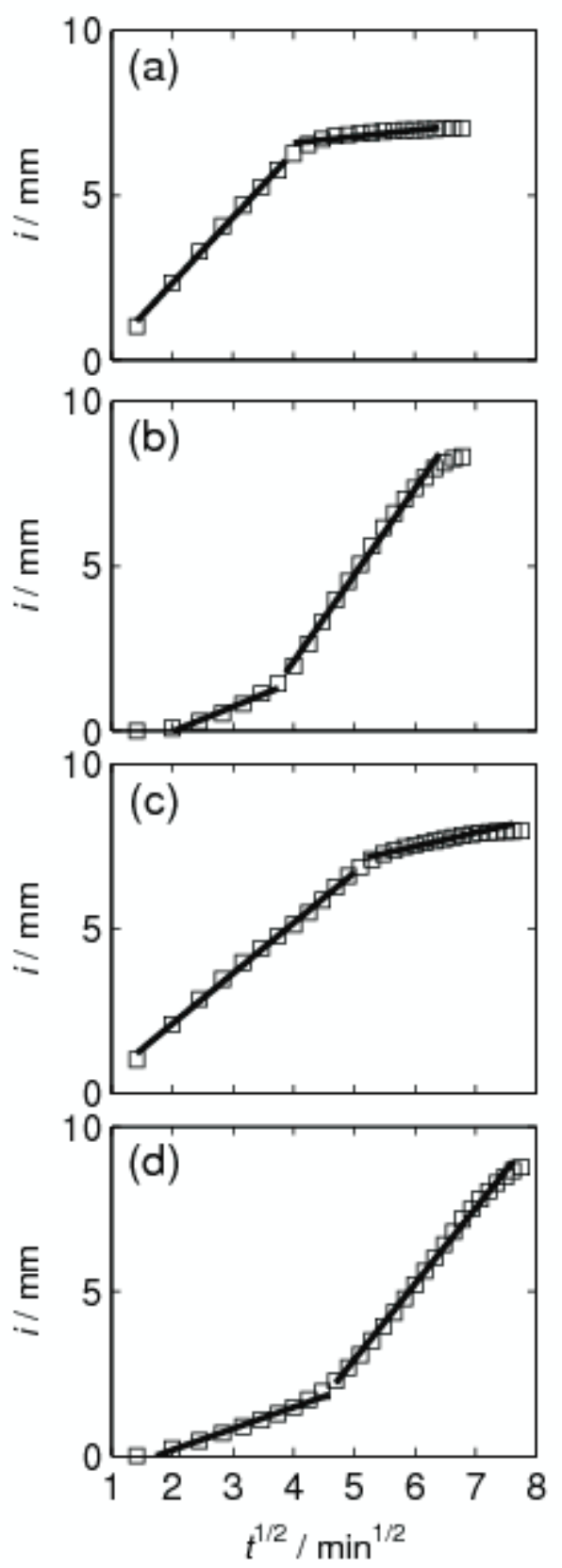

Figure 10. Plots of $i$ versus $t^{1 / 2}$ (a) from the profiles $\theta<0.19$ in sample $\mathrm{A}$ in figure 8(a), (b) from the profiles $\theta>0.19$ in sample A in figure 8(a), (c) from the profiles $\theta<0.21$ in sample B in figure $8(\mathrm{~b})$, and (d) from the profiles $\theta>0.21$ in sample B in figure $8(\mathrm{~b})$. The solid lines are least-squares linear fits to the data and the sorptivity values obtained are given in table 2 . 

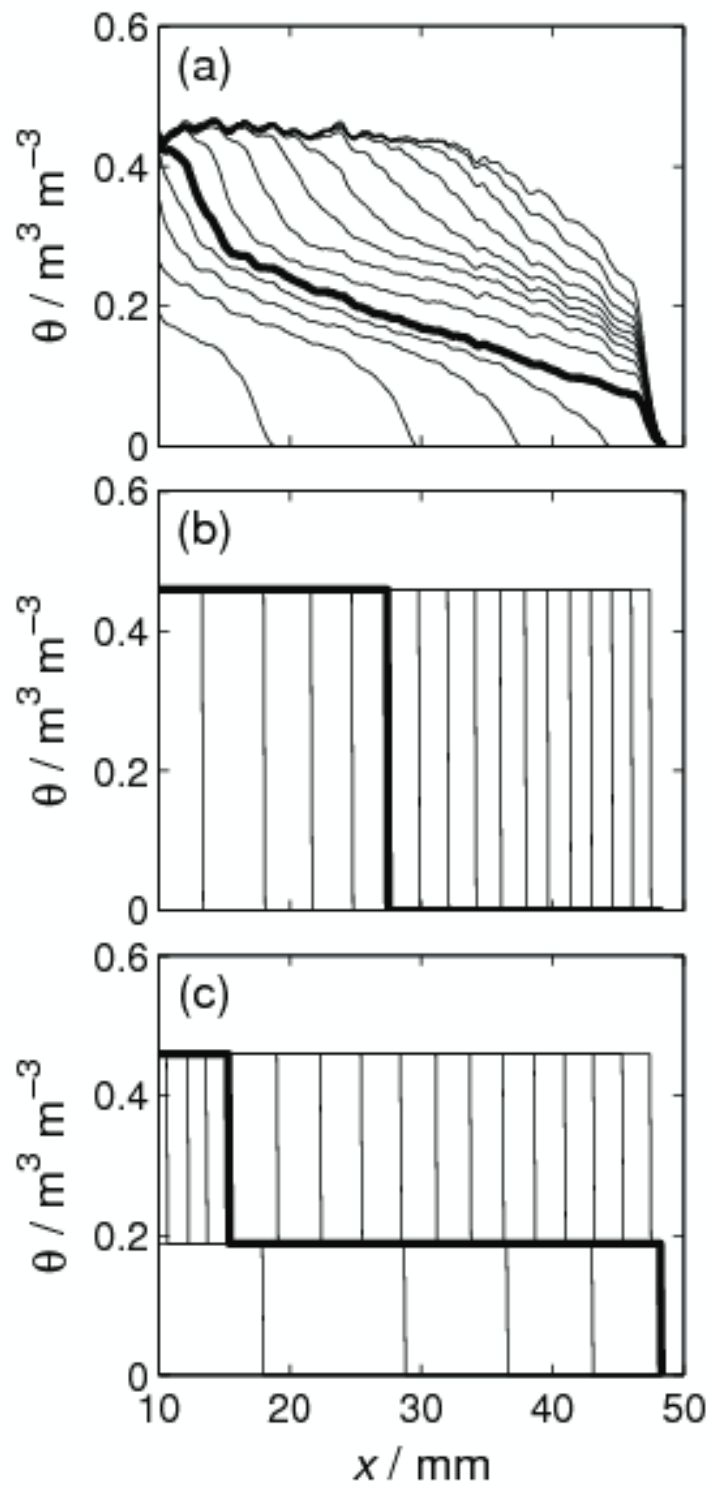

Figure 11. Comparison between the MRI water content profiles and SF simulated water content profiles for sample A: (a) MRI profiles, (b) SF analysis with a single wetting front, and (c) SF analysis with two wetting fronts. The thick line represents the profile at $t=14 \mathrm{~min}$ in each case. 


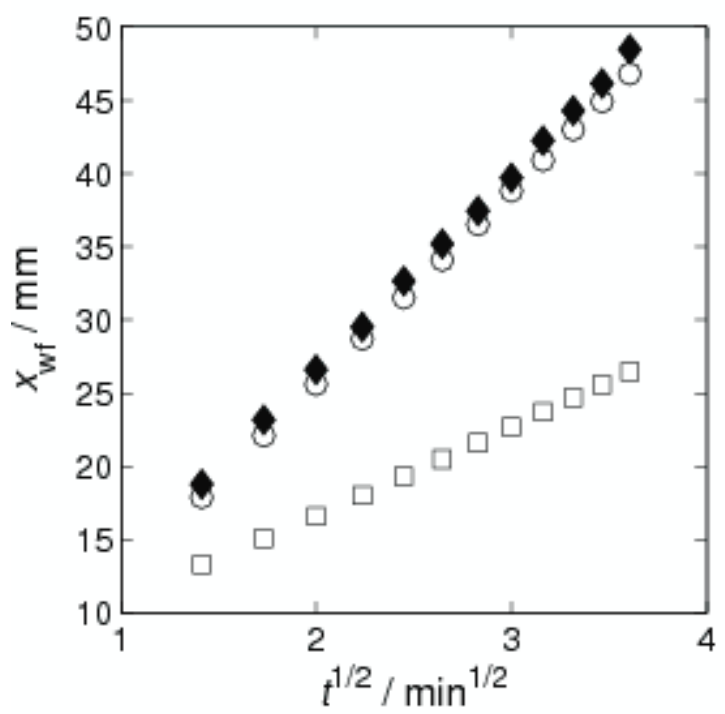

Figure 12. Comparison in the wetting front position, from figure 11, between the MRI data (solid diamond), and simulated data obtained from SF analysis with a one-component model (square) and $\mathrm{SF}$ analysis with a two-component model (circle). 

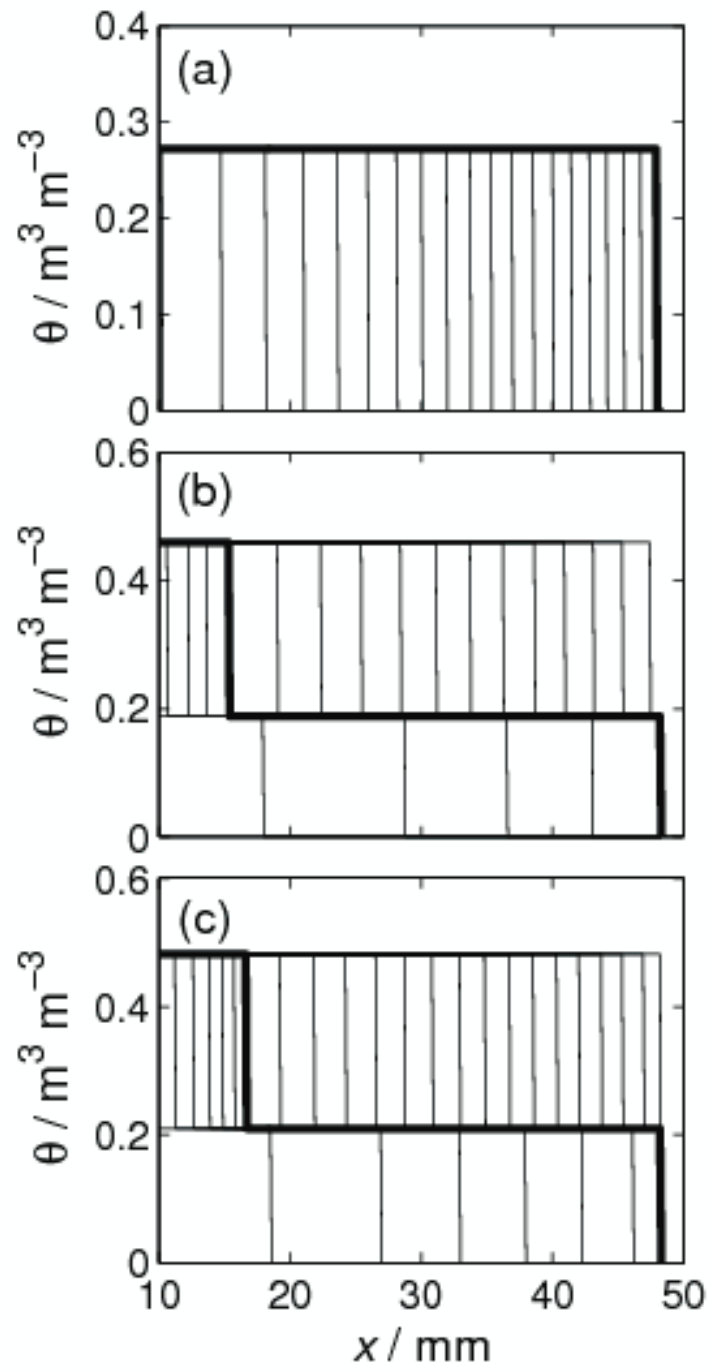

Figure 13. Water content profiles simulated using SF for (a) the reference sample with a single wetting front, (b) sample A with two wetting fronts, and (c) sample B with two wetting fronts. Thick lines represent when the wetting front first reaches the top of the sample at times (a) $t=40$ min, (b) $t=14 \mathrm{~min}$, and (c) $t=18 \mathrm{~min}$. 


\section{References}

$1 \quad$ Karni J and Karni E 1995 Mater. Struct. 28 92-100

2 Santos A G 2009 Mater. Construcc. 59 105-24

3 Çolak A 2000 Cem. Concr. Compos. 22 193-200

4 Skujans J, Vulans A, Ildis U and Aboltins A 2007 Appl. Therm. Eng. 27 1219-24

$5 \quad$ Küntz M and Lavallée P 2001 J. Phys. D: Appl. Phys. 34 2547-54

$6 \quad$ Philip J R 1957 Soil Sci. 83 345-57

7 Philip J R 1969 Adv. Hydrosci 5 215-96

$8 \quad$ Philip J R 1957 Soil Sci. 84 257-64

$9 \quad$ Hall C 1977 Build. Environ. 12 117-25

10 Gummerson R J, Hall C and Hoff W D 1980 Build. Environ. 15 101-8

11 Hall C, Hoff W D and Skeldon M 1983 J. Phys. D: Appl. Phys. 16 1875-80

12 Hall C, Hoff W D and Nixon M R 1984 Build. Environ. 19 13-20

13 Hall C and Yau M H R 1987 Build. Environ. 22 77-82

14 Ho D W S and Lewis R K 1987 Durability Build. Mat. 4 241-52

15 Carpenter T A, Davies E S, Hall C, Hall L D, Hoff W D and Wilson M A 1993 Mater. Struct. 26 286-92

16 Hall C and Kam-Ming Tse T 1986 Build. Environ. 21 113-8

17 Hall C and Hoff W D 2002 Water Transport in Brick, Stone and Concrete (London: Taylor and Francis)

18 Sabir B B, Wild S and O'Farrell M 1998 Mater. Struct. 31 568-74

19 Martys N S and Ferraris C F 1997 Cem. Concr. Res. 27 747-60

20 Hall C 1989 Mag. Concr. Res. 41 51-61

21 Ioannou I, Hamilton A and Hall C 2008 Cem. Concr. Res. 38 766-71

22 Ioannou I, Andreou A, Tsikouras B and Hatzipanagiotou K 2009 Eng. Geol. 105 20-3

23 Green W H and Ampt G A 1911 J. Agric. Sci. 4 1-24

24 Davidson I M, Biggar J W and Neilson D R 1963 J. Geophys. Res. 684777

25 Quenard D and Sallee H 1989 Mater. Res. Soc. Symp. Proc. 137 165-9

26 Descamp F 1997 Continuum and Discrete Modelling of Isothermal Water and Air Transfer in Porous Media (PhD Thesis, KULeuven, Leuven, Belgium)

$27 \quad$ Nielsen A F 1972 Build. Sci. 7 257-63

28 Kumaran M K and Bomberg M 1985 Proc. Int. Symp. on Moisture and Humidity (Washington DC) pp 485-90

29 Pel L, Ketelaars A A J, Adan O C G and Van Well A A 1993 Int. J. Heat Mass Transfer 36 1261-7

30 Pleinert H and Degueldre C 1995 J. Contam. Hydrol. 19 29-46 
31 Pražák J, Tywoniak J, Peterka F and Šlonc T 1990 Int. J. Heat Mass Transfer 33 $1105-20$

32 Hassanein R, Meyer H O, Carminati A, Estermann M, Lehmann E and Vontobel P 2006 J. Phys. D: Appl. Phys. 39 4284-91

33 El-Ghany El Abd A and Milczarek J J 2004 J. Phys. D: Appl. Phys. 37 2305-13

34 Hoff W D, Wilson M A, Benton D M, Hawkesworth M R, Parker D J and Fowles P 1994 J. Mater. Sci. Lett. 15 1101-4

35 Plagge R, Grunewald J and Haüpl P 1999 Proc. of the 5th Symp. on Building Physics in the Nordic Countries (Göteborg, Sweden) pp 337-44

36 Baker P H, Bailly D, Campbell M, Galbraith G H, McLean R G, Poffa N and Sanders C H 2007 Measurement 40 951-9

37 Kaufmann J and Studer W 1995 Mater. Struct. 28 115-24

38 Roels S, Vandersteen K and Carmeliet J 2003 Adv. Water Resour 26 237-46

39 Gummerson R J, Hall C, Hoff W D, Hawkes R, Holland G N and Moore W S 1979 Nature 281 56-7

40 Roels S, Carmeliet J, Hens H, Adan O, Brocken H, Cerny R, Pavlík Z, Ellis A T, Hall C, Kumaran K, Pel L and Plagge R 2004 J. Therm. Envelope Build. Sci. 27 261-75

41 Pel L 1995 Moisture Transport in Porous Builing Materials (PhD Thesis, TU/e, Eindhoven, The Netherlands)

42 Pel L, Kopinga K, Bertram G and Lang G 1995 J. Phys. D: Appl. Phys. 28 675-80

43 Pel L, Kopinga K and Brocken H 1996 Magn. Reson. Imaging 14 931-2

44 Pel L, Hazrati K, Kopinga K and Marchand J 1998 Magn. Reson. Imaging 16 525-8

45 Bohris A J, Goerke U, McDonald P J, Mulheron M, Newling B and Le Page B 1998 Magn. Reson. Imaging 16 455-61

46 McDonald P J, Aptaker P S, Mitchell J and Mulheron M 2007 J. Magn. Reson. 185 111

47 Chen Q, Gingras M K and Balcom B J 2003 J. Chem. Phys. 119 9609-16

48 Callaghan P T 1991 Principles of Nuclear Magnetic Resonance Microscopy (Oxford: Clarendon)

49 Reda Taha M M, El-Dieb A S and Shrive N G 2001 Mater. Struct. 34 438-45

50 Carr H Y and Purcell E M 1954 Phys. Rev. 94 630-8

51 Meiboom S and Gill D 1958 Rev. Sci. Instrum. 29 688-91

52 Munn K and Smith D M 1987 J. Colloid Interface Sci. 119 117-26

53 Wilson J D 1992 J. Mater. Sci. 27 3911-24

54 Wahba G 1977 SIAM J. Numer. Anal. 14 651-67

55 Wahba G 1982 Statistical Theory and Related Topics III ed Gupta S S and Berger J O (New York: Academic Press) pp 383-418

56 Song K M, Mitchell J and Gladden L F 2009 J. Mater. Sci. 44 5004-12 
57 Song K M, Mitchell J, Jaffel H and Gladden L F 2010 J. Mater. Sci. 45 5282-90

58 Valckenborg R M E, Pel L, Hazrati K, Kopinga K and Marchand J 2001 Mater. Struct. 34 599-604

59 Collins J H P, Gladden L F, Hardy I J and Mantle M D 2007 Appl. Magn. Reson. 32 $185-204$

60 Jaffel H, Korb J-P, Ndobo-Epoy J-P, Morin V and Guicquero J-P 2006 J. Phys. Chem. B $1107385-91$

61 Roels S, Carmeliet J, Hens H, Adan O, Brocken H, Cerny R, Pavlík Z, Hall C, Kumaran K, Pel L and Plagge R 2004 J. Therm. Envelope Build. Sci. 27 307-25

62 Collier N C, Wilson M A, Carter M A, Hoff W D, Hall C, Ball R J, El-Turki A and Allen G C 2007 J. Phys. D: Appl. Phys. 40 4049-54

63 Gummerson R J, Hall C and Hoff W D 1981 Build. Environ. 16 193-9

64 Hall C, Hoff W D and Wilson M A 1993 J. Phys. D: Appl. Phys. 26 31-4

65 Ioannou I, Hall C, Wilson M A, Hoff W D and Carter M A 2003 J. Phys. D: Appl. Phys. 36 3176-82

66 Hall C and Hoff W D 2007 Mater. World 15 24-6 